International Journal of Applied Dental Sciences 2020; 6(4): 326-329

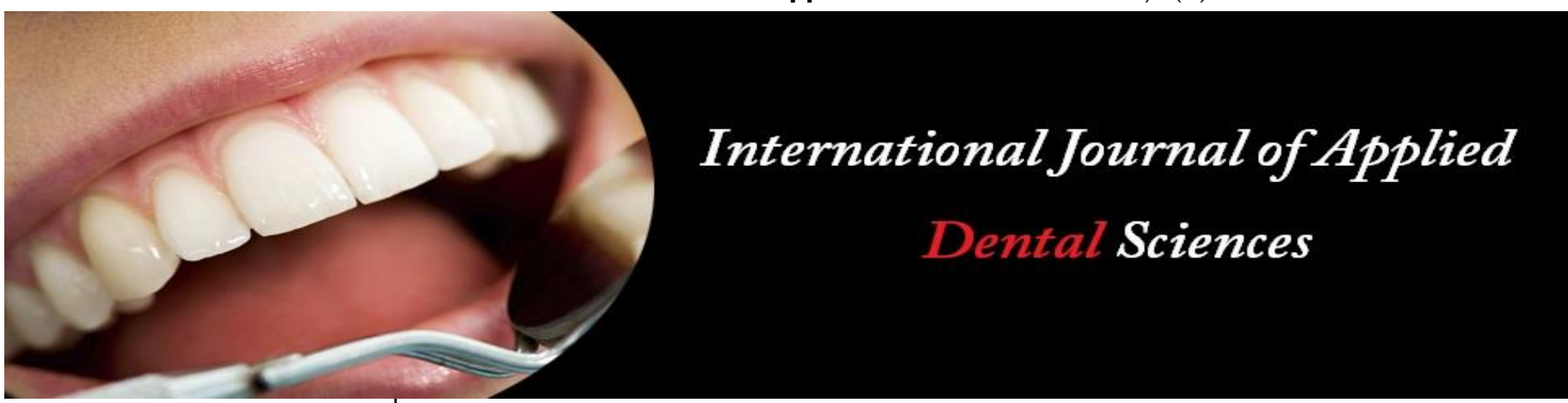

ISSN Print: 2394-7489

ISSN Online: 2394-7497

IJADS 2020; 6(4): 326-328

(C) 2020 IJADS

www.oraljournal.com

Received: 18-08-2020

Accepted: 16-09-2020

Dr. Marbon Joevitson

Department of OMFS,

Sree Mookambika Institute of

Dental Sciences, Kulasekaram,

Kanyakumari, Tamil Nadu,

India

Dr. Eshona Pearl

Senior Lecturer, Department of

Prosthodontics, Sree

Mookambika Institute of Dental

Sciences, Kulasekaram,

Kanyakumari District, Tamil

Nadu, India
Corresponding Author: Dr. Marbon Joevitson Department of OMFS, Sree Mookambika Institute of Dental Sciences, Kulasekaram, Kanyakumari, Tamil Nadu, India

\section{Earlobe Plasty: A short review}

\author{
Dr. Marbon Joevitson and Dr. Eshona Pearl
}

DOI: https://doi.org/10.22271/oral.2020.v6.i4e.1086

Abstract

Earlobe piercing is a part of each and every culture and tradition, the history of which dates back to ancient times 5000 years ago. This ancient art of body piercing has become a part of the fashion process in the recent times. 2 Latin Americans have routinely pierced the earlobes of new born girls to indicate sexual identity. 3 But nowadays, earlobe piercing is a quotidian event in all groups of population.

Individuals who are currently 20 to 25 years old are given the term Generation X (extreme). This generation $\mathrm{X}$ group of youth has distinguished themselves with extremes in sports, music, designer drugs, tattoos and body piercing. With the resurgence of ear piercing, more and more patients presents with the complications from these procedures. The most common local complications of earlobe piercings include minor infections, contact dermatitis, infection of the lobule, formation of keloid, lobular tissue loss, elongation of the earlobe, splitting of the earlobe. The repair of elongated or split earlobes is frequently done by cosmetic surgeons. There are various procedures reported in the literature for this repair.

Keywords: Elastic modulus, flexural strength, provisional restorative materials

\section{Introduction}

The earlobe is an anatomical structure with small dimensions without specific functions but it possess a notable aesthetic role ${ }^{[7]}$. Long term usage of heavy earrings results in split/torn earlobe and wide aperture/dilated/stretched earlobe. There is a variable rate of incidence in patients wearing earrings, based on the ethnicity, culture and country ${ }^{[8]}$. The most common complication seen by cosmetic surgeons is acquired cleft earlobe from usage of earrings ${ }^{[9]}$.

A variety of techniques to repair elongated and split earlobes have been reported in the literature with or without reconstructing a hole. These surgical techniques ranges from simple excision with primary closure to incorporation of purse string closure, straight line closure, straight line closure with hole preservation by Elsahy, Boo-Chai's technique, Pardue's method, straight line closure with modification to inferior rim by Harahap, Casson, Kalimuthu, Reiter and Alford, hole preservation with modification to inferior rim by Hamilton and LaRossa, Buchan, Argamaso, Fatah, Zoltie, Z-plasty, L-plasty, step advancement flap, rotation flap, bilobed flap, Gavello's technique, Reiter and Alford'd technique, earlobe reconstruction by Cheney or combination of these ${ }^{[9]}$

\section{Etiology and pathology}

Torn earlobes and elongated earlobes are known as split or complete cleft earlobes and partial or incomplete cleft earlobes respectively. This is acquired due to sudden pull of an earring, continuous traction from heavy or pendulous earrings, chronic and repeated tension on the piercing site from physical activities like jogging, running and habitual fondling [10, 11, 12]. Usage of tight clip-on earrings causes earlobe necrosis ${ }^{[10]}$. The other contributing factors include position of earring hole if placed too low, most commonly with women who were born in 1960's and earlier, where it was a custom to pierce the earlobe in the lower third. Larger and much more severe earlobe defects results from traumatic animal bite or human bite [1]. Congenital earlobe defects/clefts are also reported in the literature but it is very rare ${ }^{[9,13]}$. It has been described as unilateral or bilateral and typically involving the soft tissue of the lobule, sparing the auricular cartilaginous framework ${ }^{[9]}$. Elongated earlobe is a result of gradual and chronic stretching of the earlobe by heavy earrings which causes tissue expansion like effect with an intact earlobe. 
Split earlobe occurs as a result of constant and gradual splitting of the earlobe which leads to complete separation. A split can occur in one earlobe and then later develop in the other ear or it can occur simultaneously on both ears. There is no age predilection. Most commonly occurs in females with the usage of earrings. Mostly this split is associated with moist discharge and/or itching of variable intensity. The histological study of the split tissue reveals an inflammatory reaction with perivascular infiltration of lymphocytes, plasma cells, eosinophils and some degree of granulomatous reaction is also reported in the literature ${ }^{[2]}$.

A strong evidence of allergic reaction to gold is also reported in the literature. But allergy to pure gold is very rare. Allergic reactions to nickel, copper and zinc are very common. The 3 ways in which allergic reactions to earrings can manifest include: [1] a weeping eczematous reaction of the skin surrounding the pierced hole of the earlobe; ${ }^{22}$ gradual splitting of the earlobe; ${ }^{3]}$ a keloid-like lesion. 2 The other common local complications involved in split earlobes include allergic contact dermatitis, inflammation, bleeding, infection, crusting and cyst formation ${ }^{[1]}$.

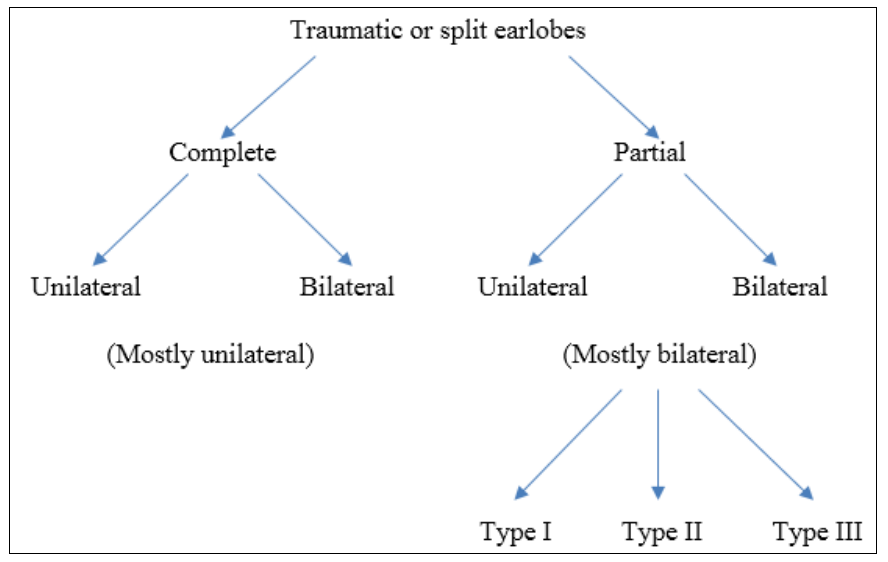

Fig 1: Classification

Mostly complete clefts are unilateral and partial or incomplete clefts are bilateral. Blanco-Davila and Vasconez have subclassified incomplete or partial clefts into ${ }^{[3]}$.

Type I: The boundaries of the cleft hole extends less than half the distance between the original piercing and the inferior margin of the earlobe.

Type II: The boundaries of the cleft hole extends more than half the distance between the original piercing and the inferior margin of the earlobe.

Type III: The cleft hole completely splits the earlobe.

Eleven pearls for cosmetic earlobe repair ${ }^{[4]}$.

Pearl 1: Control of the earlobe facilitates precision repair

Pearl 2: Precision cutting of the mobile earlobe is best performed with a pressureless incisional modality

Pearl 3: Small tears in the upper two-thirds of the earlobe may be simply excised

Pearl 4: Incomplete tears that are at or below the junction of the lower one-third of the earlobe should be converted to a full tear

Pearl 5: When repairing a full-thickness earlobe tear, utilize one or two resorbable deep sutures

Pearl 6: Before final closure, place a key suture on the most inferior portion of the earlobe

Pearl 7: Close the lateral surface of the incision first

Pearl 8: Immediate re-piercing is a simple procedure that provides increased patient satisfaction

Pearl 9: All ear piercings must be perpendicular to the long axis of the earlobe

Pearl 10: Common complications are easy to correct or prevent

Pearl 11: Earlobe tears are easier to prevent than to treat

Prevention of earlobe tears ${ }^{[4]}$.

- Avoid wearing heavy earrings for long time periods

- Remove earrings when using the telephone

- Remove earrings at the hair salon

- Be aware that small children and babies are attracted to earrings

- Remove your earrings before removing upper clothing like sweaters

- Do not allow children to wear small loop or dangling earrings.

\section{Surgical techniques}

A variety of techniques to repair elongated and split earlobes have been reported in the literature with or without reconstructing a hole. These surgical techniques ranges from simple excision with primary closure to incorporation of purse string closure, straight line closure, straight line closure with hole preservation by Elsahy, Boo-Chai's technique, Pardue's method, straight line closure with modification to inferior rim by Harahap, Casson, Kalimuthu, Reiter and Alford, hole preservation with modification to inferior rim by Hamilton and LaRossa, Buchan, Argamaso, Fatah, Zoltie, Z-plasty, Lplasty, step advancement flap, rotation flap, bilobed flap, Gavello's technique, Reiter and Alford'd technique, earlobe reconstruction by Cheney or combination of these ${ }^{[9]}$.

\section{Discussion}

Numerous techniques have been described to repair the torn earlobe. The different surgical techniques have been mentioned. There are many techniques to repair the partial cleft earlobe. Straight line closure is a simple and faster technique when compared to other surgical techniques, but it does not provide the best cosmetic results. The various surgical procedures for repair of partial and total cleft earlobe range from simple scar revision with approximation of edges to the use of different types of flaps and closure. Each procedure has its own merits and demerits. Some procedures are simple while others are more complicated and time consuming.

\section{Conclusion}

Cleft earlobe whether it is partial or complete, it can be corrected by using any of the above mentioned surgical techniques or a combination of those. The procedure can be done under local anaesthesia. There should be a clear understanding of the anatomy of the earlobe, advantages and disadvantages of each technique. This should be applied accordingly in each case by the surgeon. Educating the patient about preventing future clefts is mandatory. They should be advised not to wear heavy earrings, and for a long time period of time, to remove the earrings at night.

\section{References}

1. Deborah Watson. Repair of torn earlobe. Facial Plastic Surgery 2004;20:1.

2. Sherine Subodhini Raveendran, Lalantha Amarasinghe. The mystery of the split earlobe. Plast. Reconstr. Surg 2004.

3. Blanco-Davila F, Vasconez HC. The cleft earlobe: a review of methods of treatment. Ann Plast Surg 
1994;33:677-680.

4. Joesph Niamtu. Eleven pearls for cosmetic earlobe repair. Dermatol Surg 2002;28:2.

5. Apesos J, Kane M. Treatment of traumatic earlobe clefts. Aesthet Plast Surg 1993;17:253-255.

6. Hendricks WM. Complications of ear piercing: treatment and prevention. Cutis 1991;48:386-394.

7. Ana Rita Cabral, Neide Alonso, Ana Brinca, Ricardo Vieira, Américo Figueiredo. Earlobe reconstruction by the Gavello technique and bilobed flap. An Bras Dermatol 2013;88(2):272-5.

8. Harish MO, Chethana R. Step advancement flap technique of ear lobe repair. Int J Otorhinolaryngol Head Neck Surg 2018;4(1):154-158.

9. Boo-Chai K. The cleft ear lobe. Plastic and Reconstructive Surgery 1961;28:681-688.

10. McLaren LR: Cleft earlobe: A hazard of wearing earrings. Br J Plast Surg 1954;7:162-165.

11. Pardue AM: Repair of the torn earlobe with preservation of the perforation for an ear- ring. Plast Reconstr Surg 1973;51:472-473.

12. Reiter D, Alford EL: Torn earlobe: A new approach to management with a review of 68 cases. Ann Otol Rhinol Laryngol 1994;103:879-884.

13. Blanco-Davila F, Vasconez HC: The cleft earlobe: A review of methods of treatment. Ann Plast Surg 1994;33:677-680. 